\title{
Experimental study of flow pattern and sediment behavior near the intake structures using the spur dike and skimming wall
}

\author{
Amir Moradinejad $^{1} \cdot$ Mojtaba Saneie $^{2} \cdot$ Amir Ghaderi $^{3}\left[\right.$ Seyed Mahyar Zamanieh Shahri ${ }^{4}$
}

Received: 31 May 2019 / Accepted: 3 October 2019 / Published online: 25 October 2019

(c) The Author(s) 2019

\begin{abstract}
Channel junctions and lateral intakes are always caused turbulence in the passing flow. In this research, an experimental study was carried out to explore a possible method for sediment control for a series of skimming walls and a single spur dike, simultaneously. In order to direct the flow into the diversion channel and increase the skimming wall function, a single spur dike was utilized at the opposite side of the intake channel. The flow patterns for three conditions, including (1) without structures, (2) with skimming wall and (3) skimming wall and spur dike, are considered. The results showed that the use of skimming wall and a combination of skimming wall and spur dike makes it possible to direct the thalweg toward the intake port. In addition, by using the skimming wall, a trench is made toward the intake, which in turn increases the impoundment efficiency by $81 \%$ in the skimming wall combined with spur dike and up to about $66 \%$ for using the skimming wall.
\end{abstract}

Keywords Intake port $\cdot$ Spur dike $\cdot$ Sediment efficiency $\cdot$ Skimming wall

\section{Introduction}

Intake structures divert some portion of the flow from rivers and may cause some changes in hydraulic conditions of the flow at the entrance. Because of changes taking place in the distribution of velocity in the intake port zone, sedimentation usually occurs at the intake port, which causes a decrease in intake flow and in the entrance of the coarse sediment into the facility served by the intake (irrigation canal, power plant, etc.). In order to control the sediments in the intakes, which is considered as a complex issue in river engineering, various structures are used. Spur dikes are simple hydraulic structures which are used to organize river bends or their straight line. They are used to control erosion and protect river banks and are of the deviation type

Amir Ghaderi

amir_ghaderi@znu.ac.ir

1 Soil Conservation and Watershed Management Research Department, Arak, Iran

2 Soil Conservation and Watershed Management Institute, Tehran, Iran

3 Department of Civil Engineering, Faculty of Engineering, University of Zanjan, Zanjan, Iran

4 Department of Civil Engineering, Khavaran Institute of Higher Education, Mashhad, Iran
(Moradinejad et al. 2017; Daneshfaraz et al. 2015). This structure causes changes in the flow pattern due to the reduction in the flow separation at the bottom. The complexity of flow and sediment transport around the intake entrance has caused research in this area to be continued. Studies by Marelius and Sinha (1998) and Kuhnle et al. (1999) showed that the intensity of entering the bed sediments into the intake can be negligible after installing the submerged vanes. During the past several decades, many researchers studied the different aspects of vanes' design for sediment control at intake, e.g., Wang et al. (1996), Sinha and Marelius (2000) and Odgaard and Kennedy (2009). Nakato et al. (1990) conducted sediment management in intake entrance with using submerged vanes in Station 3 of Plant Council Blafsz is located on the Missouri River for the first time. The results showed that submerged vanes are an appropriate solution for the reduction of sediment deposition in intake entrance. Neary et al. (1999) developed a 3D numerical model of a $90^{\circ}$ intake in a rectangular channel and verified this model using experimental results. According to their findings, as the flow diversion ratio increases, the width of the vortex area and its length first decreases and then increases. Zahabi et al. (2018) indicated the effect of reservoir shapes on the sediment entrapment and the vortices in the tank. Ramamurthy et al. (2007) demonstrated that increasing the flow diversion ratio reduces the length and width of the flow separation zone in 
the intake channel. Also, the width of the separation zone in the intake channel in the bottom is less than the surface. Yonesi et al. (2008) studied the effects of the longitudinal arrangement of submerged vanes on the sediment behavior near the intake structures. Their results showed that using submerged vanes makes it possible to direct the thalweg toward the intake. Choufu et al. (2019) investigated the erosion, and sedimentation pattern around varied groynes. In this study, the application of skimming wall and its effect on controlling sediment entering intakes have been investigated. Skimming wall is a structure consisting of two plates connected to the bank with a specified angle. Figure 1 shows (a) plan and (b) cross section of a skimming wall.

Considering the literature review, most studies have been conducted on submerged vanes, sill, spur dike or a combination of them in intakes. Therefore, more studies are required in this area, especially, when the skimming wall is used in the intake entrance. In addition, to represent the effect of the skimming wall on the amount of sediment entering to the intake, it is required to use a combination of wall and spur dike and compare this state with no-structure conditions. Therefore, the main aim of this study was to investigate the effect of skimming wall on controlling sediment entering the lateral intake with an angle of $60^{\circ}$ from the rectangular channel. In this study, the possibility of application of submerged vanes in controlling the flow direction and directing the river thalweg toward the intake port is also considered. This research explores the effect of the skimming wall on increasing the flow rate in the intake and the reducing sedimentation in the intake compared with conditions in which no skimming wall was used. It should be mentioned that the velocity distribution at the intake port has been measured.

\section{Dimensional analysis}

Using dimensional analysis and Buckingham method, considering related parameters, a series of non-dimensional relations are obtained. Many parameters that affect the flow entering the intake (Hosseini et al. 2019) include: flow discharge in main channel $\left(Q_{\mathrm{m}}\right)$, flow discharge in intake channel $\left(Q_{1}\right)$, sediment discharge in main channel $\left(Q_{\mathrm{sm}}\right)$, sediment discharge in intake channel $\left(Q_{\mathrm{sl}}\right)$, flow depth in main channel $(d)$, flow velocity in main channel $\left(V_{\mathrm{m}}\right)$, width of main channel $\left(B_{\mathrm{m}}\right)$, width of intake channel $(b)$, slope of main channel $\left(S_{\mathrm{m}}\right)$, acceleration of gravity $(g)$, flow density $(\rho)$, fluid kinematic viscosity $(\nu)$, angle between intake channel and main channel $(\theta)$, angle between spur dike and bank of main channel $(\alpha)$, spur dike length $\left(L_{\mathrm{D}}\right)$, angle between skimming wall and the bank $\left(\beta_{1}\right)$, angle between two sides of skimming wall $\left(\beta_{2}\right)$, height of skimming wall plates $(H)$, length of primary branch of skimming wall $\left(L_{1}\right)$, length of second branch of skimming wall $\left(L_{2}\right)$, time of experiment $(t)$, mean diameter of sediments $\left(d_{50}\right)$, sediments density $\left(\rho_{\mathrm{s}}\right)$, bed roughness $\left(K_{s}\right)$. Since $\theta, B_{\mathrm{m}}, g, d_{50}, \rho_{\mathrm{s}}, \rho, \nu, H, t, S_{\mathrm{m}}, K_{s}$, $L_{\mathrm{D}}, L_{1}, L_{2}, \beta_{1}$ and $\beta_{2}$ are constant, using dimensional analysis, Buckingham method and removing constant parameters, final non-dimensional relation is as follows:

$G_{\mathrm{r}}=f\left(F r, Q_{\mathrm{r}}\right)$

$G_{\mathrm{r}}=Q_{\mathrm{sl}} / Q_{\mathrm{sm}}:$ ratio of discharge of sediment entering intake channel to discharge of sediment entering the main channel; $Q_{\mathrm{r}}=Q_{L} / Q_{\mathrm{m}}$ : ratio of discharge of intake channel to main channel discharge (intake ratio); and $F r$ : Froude number of flow in upstream of intake. Torabi et al. (2019) also used Froude number as a dimensionless number on their research about the effect of geometry and flow characteristics on sedimentation in the channel's junction. Therefore, we can infer that Froude number is an influential number in sediment pattern and we used this number in this research.

\section{Materials and methods}

In order to evaluate different conditions, including (1) no structures, (2) with skimming wall and (3) combination of skimming wall and spur dike, and investigate their effects on river bed topography, some experiments were conducted in a flume with a length of $15 \mathrm{~m}$, width of $1.5 \mathrm{~m}$ and height of $0.9 \mathrm{~m}$. The flume wall was made of Plexiglas with a thickness of $1 \mathrm{~cm}$. In these experiments, the flume floor was made
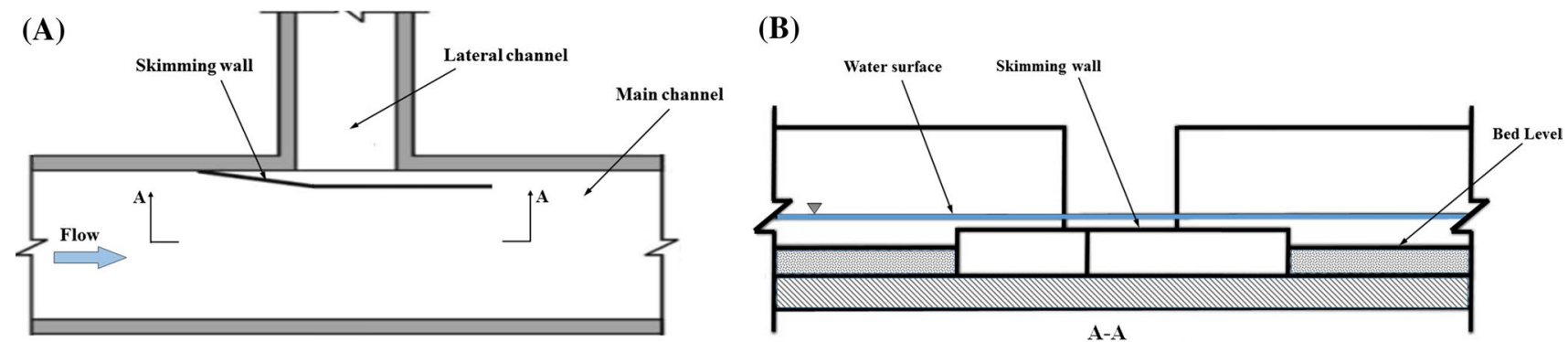

Fig. 1 a Plan view, b cross section of skimming wall (Barkdoll et al. 1999) 


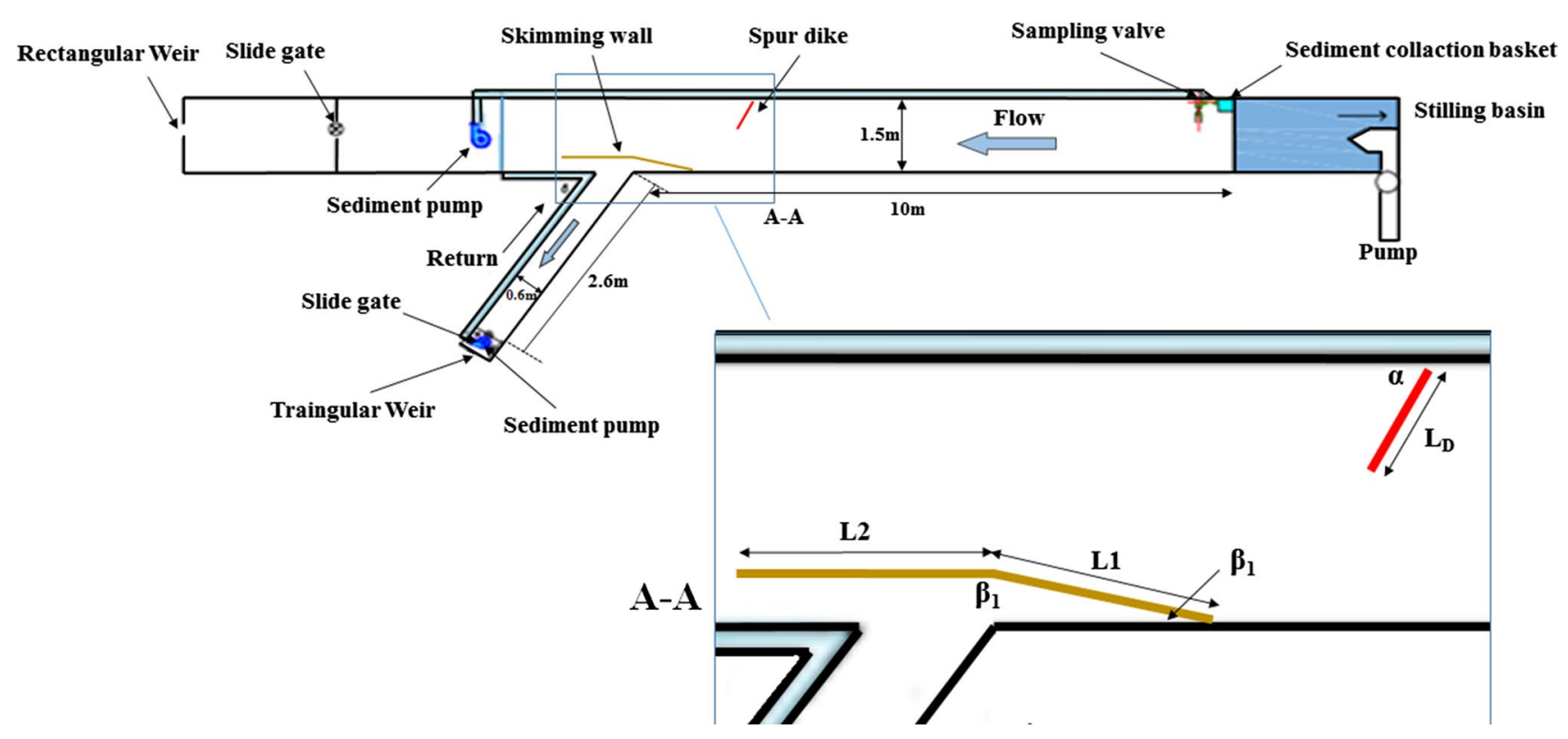

Fig. 2 A schematic view of the flume, spur dike, skimming wall and water circulation system and sediment bed

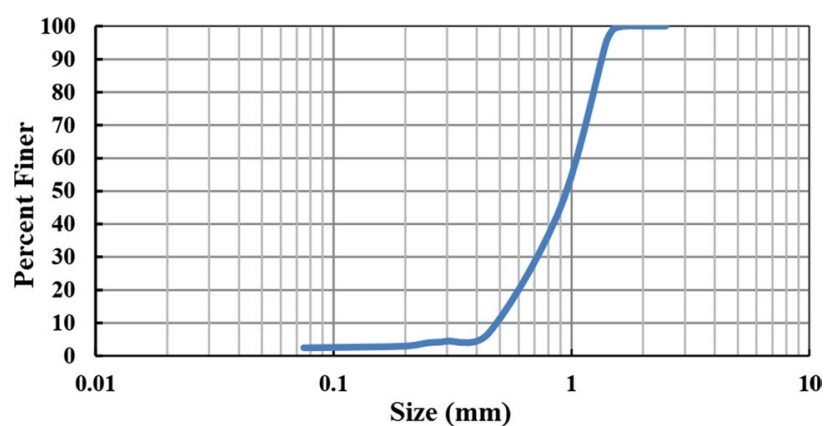

Fig. 3 Grading diagram of sediments

of concrete and the sedimentary bed was set with a slope of 0.002. Lateral channel with a length of $2.5 \mathrm{~m}$, the width of $60 \mathrm{~cm}$ and an angle of $60^{\circ}$ was installed as intake (Fig. 2). At the end of main and lateral channels, two gates were installed for water surface control and discharge measurements. Torabi and shafieefar (2015) used the laser measurement to capture the eroded profile; same methodology is used in this research to obtain the topography. Grading curve of bed materials as in Ghaderi and Abbasi (2019) study's and properties of the bed material are shown in Fig. 3 and Table 1, respectively. In Table 1, $n$ is Manning's roughness coefficient, $\varphi$ is the angle of repose for sediments, $\sigma_{\mathrm{g}}$ is the geometric standard deviation of sediment, $C_{\mathrm{u}}$ is uniformity coefficient of the sediment, $D_{\mathrm{g}}$ is the geometric mean diameter of sediment, and $D_{50}$ is the median size of the sediments.

The water circulation system is rotational, and the reservoir located below the flume supplies the required water. The inflow rate is controlled in the pumping station by the adjustable valves. Flow depth is set by a gate located at the end of each main and intake channels. To measure the flow rate in the main and the intake channels, rectangular and triangular sharp-crested weirs were used. For measuring the velocity and direction of flow, a two-dimensional electromagnetic velocimeter (made by the Delft Hydraulic Institute) was used with an accuracy of $\pm 0.001 \mathrm{~m} / \mathrm{s}$. The water surface profiles as Daneshfaraz et al. (2019) study's were measured using point gauge with the accuracy of $\pm 0.1 \mathrm{~mm}$. The velocity values were measured from $3 \mathrm{~m}$ above the centerline of the intake to $2 \mathrm{~m}$ below it. Skimming wall is composed of two parts. The first part with a length of $75 \mathrm{~cm}$ and a height of $25 \mathrm{~cm}$ is connected to the intake. One side of the first part is connected to the intake bank with an angle of $10^{\circ}$, and the other side is connected to the second part of the skimming wall. The second part parallel to the bank with a length of $112 \mathrm{~cm}$ and a height of $25 \mathrm{~cm}$ continues in line with the flow (Fig. 4). Based on Bark doll's study, the length ratio of $L_{2} / L_{1}$ was considered as 1.5 . One-third of skimming wall is outside the sedimentary bed. The spur dike used in this study has $0.25 B_{\mathrm{m}}$ length $(37.5 \mathrm{~cm})$ with an angle of $60^{\circ}$
Table 1 Properties of the bed material

\begin{tabular}{lllllll}
\hline$n$ & $\varphi^{\circ}$ & $G_{\mathrm{s}}$ & $\sigma_{\mathrm{g}}$ & $C_{\mathrm{u}}$ & $D_{\mathrm{g}}(\mathrm{mm})$ & $D_{50}(\mathrm{~mm})$ \\
\hline 0.0138 & 33 & 2.65 & 1.36 & 2.2 & 1.6 & 1 \\
\hline
\end{tabular}



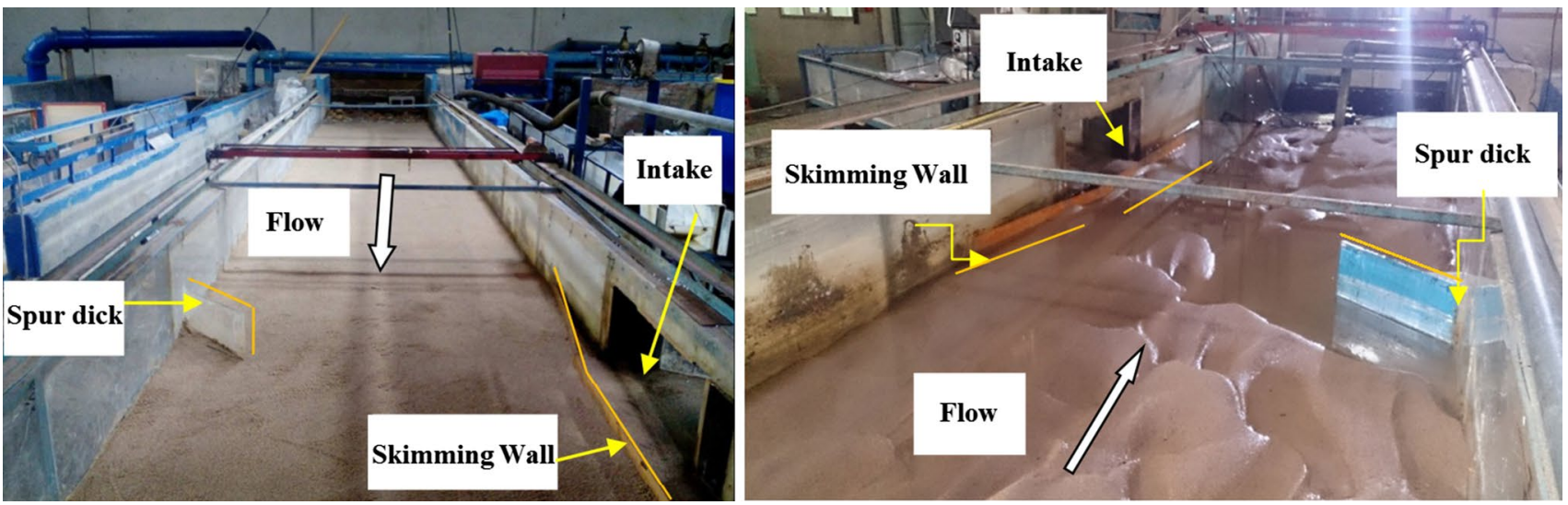

Fig. 4 A schematic view of flume, spur dike, skimming wall and sediment bed

Table 2 The parameter range in this study

\begin{tabular}{lllllll}
\hline Parameters & $\begin{array}{l}Q \text { in main channel } \\
\left(\mathrm{m}^{3} / \mathrm{s}\right)\end{array}$ & $\begin{array}{l}Q \text { in lateral channel } \\
\left(\mathrm{m}^{3} / \mathrm{s}\right)\end{array}$ & Flow depth in main channel $(\mathrm{m})$ & $F r$ & $Q_{\mathrm{r}}$ & $G_{\mathrm{r}}$ \\
\hline Range & $0.03-0.06$ & $0.005-0.010$ & $0.075-0.11$ & $0.41-0.47$ & $0.108-0.162$ & $0.034-0.318$ \\
\hline
\end{tabular}

of the main channel wall. Table 2 shows the values of the parameter changes.

Sampling was conducted from sediments entering the main and intake channels using a sieve with a diameter less than $0.1 \mathrm{~mm}$. Sediments were weighted after $30 \mathrm{~min}$. Like study Moradinejad et al. (2017), to control sediments movement as bed load in selected discharge range, Shields diagram was used. The experimental conditions were as follows: minimum discharge: $0.025 \mathrm{~m}^{3} / \mathrm{s}$, slope of moving bed: 0.002 , flow depth: $4.6 \mathrm{~cm}$, hydraulic diameter: $0.0452 \mathrm{~m}$, shear velocity: $0.0298 \mathrm{~m} / \mathrm{s}$, boundary Reynolds $(\operatorname{Re} *): 25.48$ and Shields parameter $(\theta)$ : 0.0548. According to Shields parameter $(\theta)$ and boundary Reynolds $\left(\operatorname{Re}^{*}\right)$, and considering Shields diagram, Shields parameter is higher than critical Shields parameter $\left(\theta>\theta_{\text {cr }}\right)$; therefore, bed sediments move in this discharge and higher values. In this study, a method called sediment circulation system is used in the experiments. Both sections of main channel and intake have sediment circulation system so that the total sediment exited from the intake and the main channel and some part of the water flow was injected by the sediment pump after joining each other at the beginning of the main channel. This system reaches equilibrium after a while; i.e., sediment entering the channel will be equal to sediment leaving the channel. Measurements and data records are conducted after the equilibrium of water and sediment flow. In these experiments, equilibrium time is when the sediment entering at the entrance of the main channel from the intake and the end of the channel is relatively the same. This was conducted using sampling in both paths at various intervals. To determine the

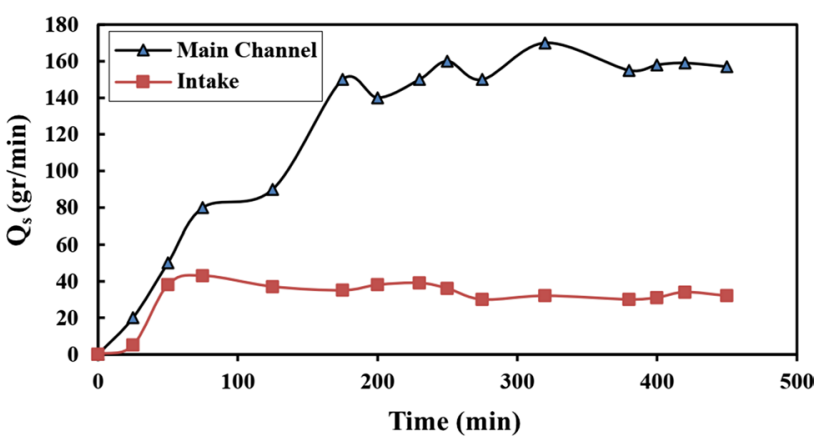

Fig. 5 Sediment discharge changes in time

equilibrium time, sampling from the sediments of the main and intake channels was conducted during experiments. Equilibrium time diagram is shown in Fig. 5.

\section{Results and discussion}

\section{Effects of skimming wall on river topography}

Figures 6, 7 and 8 show bed topography in the main channel with three conditions. As can be seen in Fig. 6, the erosion and sedimentation patterns are similar to those in a river bend. The flow in the bend creates a downward flow near the bank downstream of the intake. Finally, similar to inner and outer curves in the natural rivers, the centrifugal force induced by the turning flow may cause the erosion of the bed in the bank opposite to the intake. The results showed that 
Fig. 6 Bed topography in the main channel without skimming wall $\left(Q=0.06 \mathrm{~m}^{3} / \mathrm{s}\right)$

Fig. 7 Bed topography in the main channel with skimming wall $\left(Q=0.06 \mathrm{~m}^{3} / \mathrm{s}\right)$
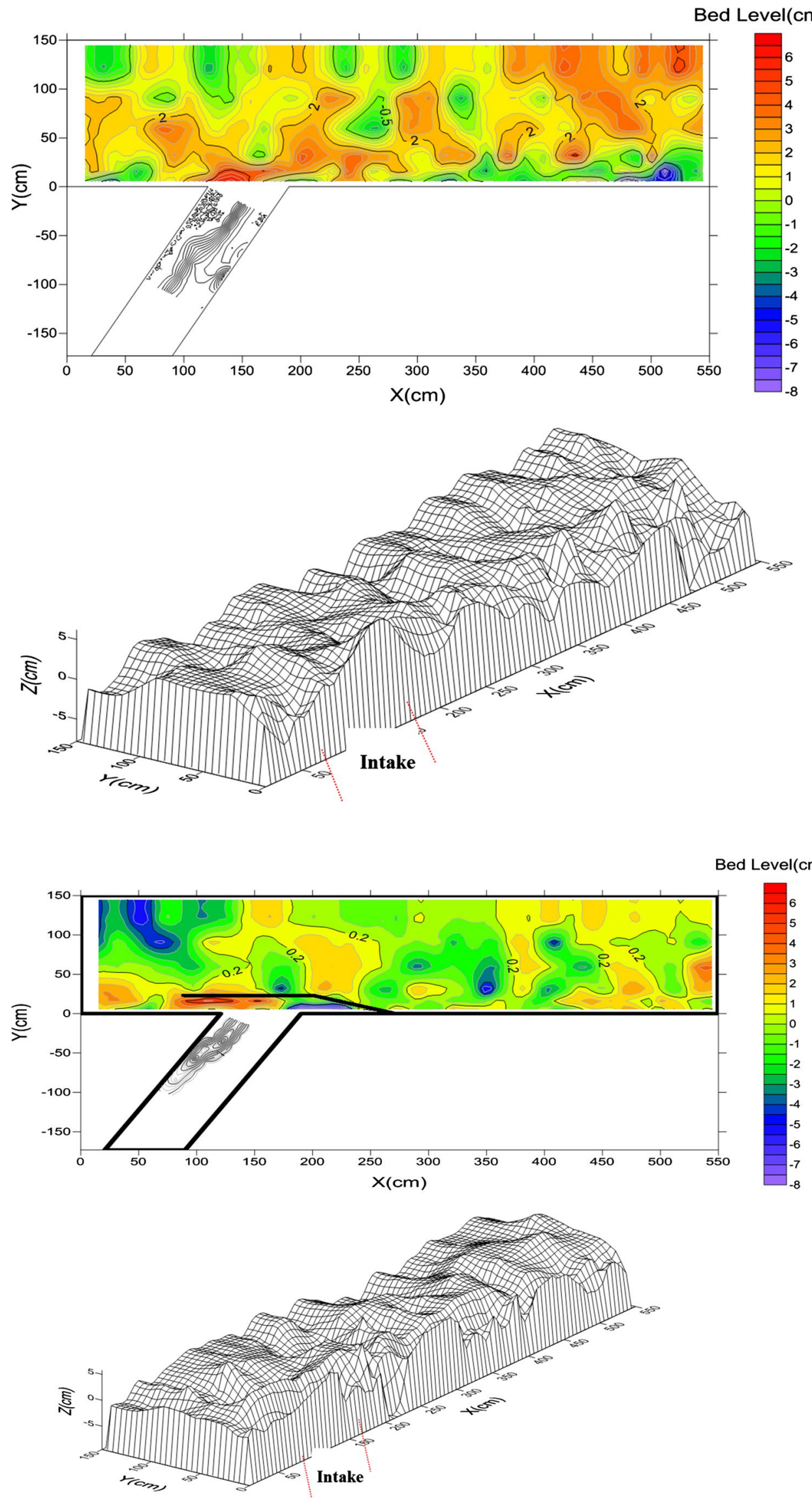
Fig. 8 Bed topography in the main channel with skimming wall and spur dike $\left(Q=0.06 \mathrm{~m}^{3} / \mathrm{s}\right)$
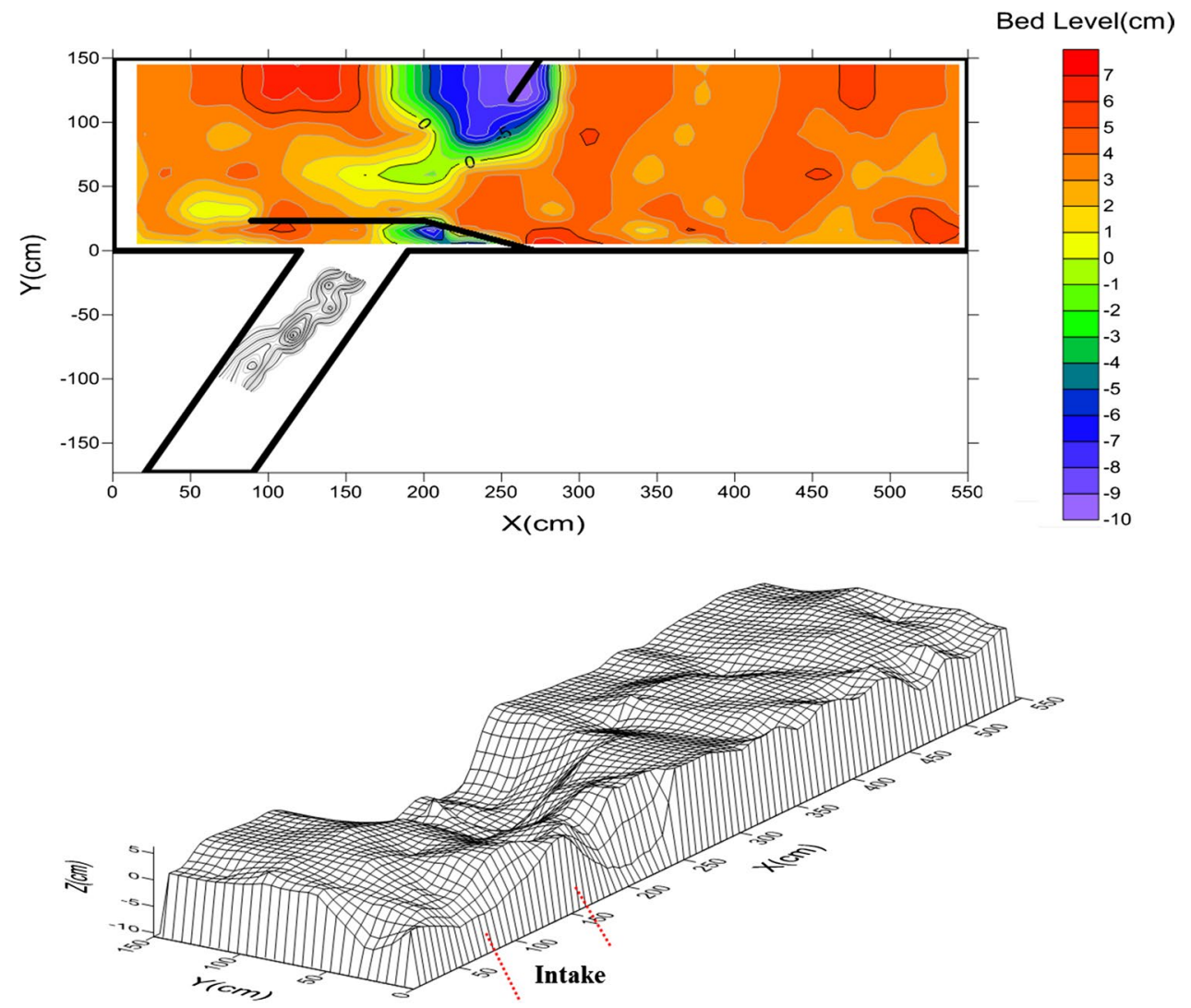

the installation of skimming wall and spur dike changes the river bed morphology that varies with the arrangement and longitudinal distance between skimming wall and spur dike. Changes the river bed morphology with used the skimming wall and spur dike caused the creation of secondary currents and change the velocity distribution, flow depth, and rate of sediment transport. Besides, the bed load is directed away from the bank and surface flow is directed into the intake.

Figure 9 shows the cross section in the upper entrance $(X=10 \mathrm{~m})$ and lower entrances $(X=10.7 \mathrm{~m})$. Also in Fig. 10, the transverse profile of bed in the main channel in upper and lower with and without skimming wall has been compared. Bed cross section in the upper entrance $(X=10 \mathrm{~m})$ can be divided into six sections. The first section is from intake bank to skimming wall that is $(0-13 \mathrm{~m})$. In this region, as the flow enters the section and over skimming wall, it removes sediments behind the structure and moves them into the intake. After a while, this section deepens and degradation continues to the end of the experiment. In some experiments, degradation depth reaches the floor of the channel. In all experiments, a major part of sediments delivered into the intake is related to behind the skimming wall (from intake bank to the skimming wall). In the second section, starting from in front of skimming wall to the transverse distance of $45 \mathrm{~cm} \mathrm{(13-45} \mathrm{m),} \mathrm{sediment} \mathrm{accumulation} \mathrm{occurs.} \mathrm{Since}$ the skimming wall is higher compared to the bed layer, no

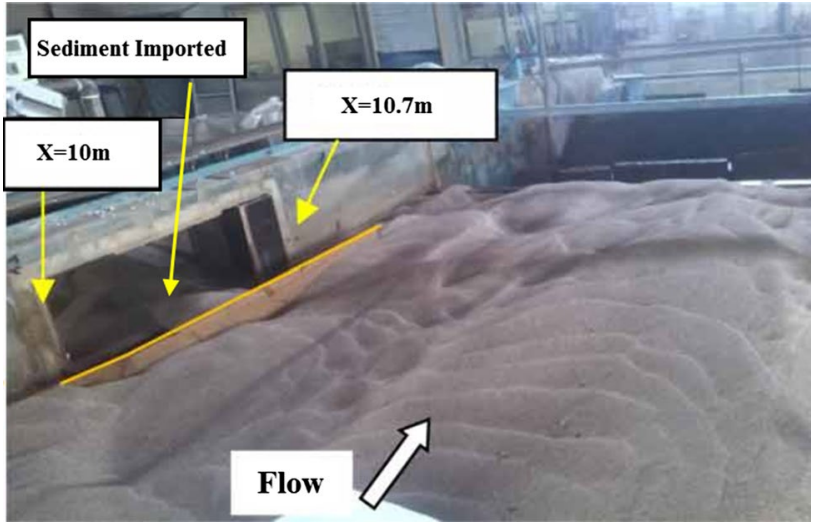

Fig. 9 Cross section in upper entrance $(X=10 \mathrm{~m})$ and lower entrances $(X=10.7 \mathrm{~m})$ in main channel

sediment enters the channel. However, because of the turbulence in the inlet area of intake as well as deposition of sediments and creation of a slope at the skimming wall toe, sediments slide on this slope and enter intake channel (Fig. 9). Although the skimming wall does not control all sediments, a significant decrease is observed in sediments entering the intake. The third section is from a transverse distance of 45 to $70 \mathrm{~cm}$. In this section, flow velocity increased by installing spur dike in the opposite bank side and above the 

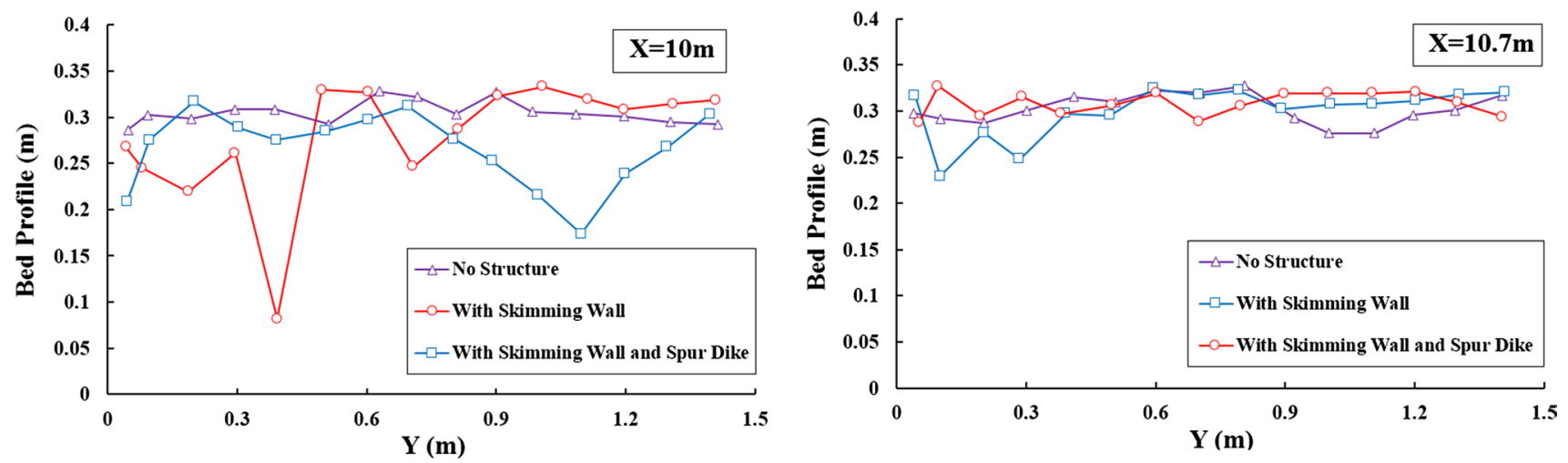

Fig. 10 Bed topography at the intake entrance with and without skimming wall and spur dike

intake that enforces skimming wall performance and creates strong secondary flow and sediments are prevented from entering the intake. This secondary flow in the channel floor is against intake flow on the surface toward the intake. Concurrent existence of intake and spur dike in the opposite bank results in transverse dislocation of maximum speed and therefore dislocation of thalweg. Dislocation of maximum transverse velocity starts from upstream of spur dike and reaches its maximum value in front of intake because of flow accelerating in the intake. The fourth section is from transverse distance of 70 to $90 \mathrm{~cm}$. This area is strongly affected by spur dike. Near spur dike, as the power of secondary flow increases, sediments are removed from that area and are transferred to the downstream of spur dike. Near the nose of spur dike, the average vertical component of speed is enforced and washes the sediments and transfers them to the downstream of spur dike. Maximum height of sediment accumulated behind spur dike increases to $50 \mathrm{~mm}$ or $30 \%$ of a total height of sediments. The reason for this can be reduced width of flow separation by installing spur dike, the width of flow separation line is high in the floor because of high concentration of sediments on the floor, and a high volume of sediments enter intake by intake suction. The fifth section is from transverse distance of 90 to $130 \mathrm{~cm}$. Scouring effect of spur dike nose continues in this section; however, it is not observed in profile related to control degradation. The sixth section is from transverse distance of 130 to $150 \mathrm{~cm}$. No scouring occurs in this section, and sediment accumulation is observed. As can be seen in Fig. 10, in transverse area of upper entrance, the highest scouring in front of intake is transverse distance of 30-45 related to skimming wall alone and in transverse area of 90-130 related to the combination of spur dike and skimming wall. Investigating cross section of bed in lower entrance $(X=10.7)$ that the difference between this entrance and upper entrance is in first and second sections. In the first section, the transverse distance of zero to the structure behind skimming wall in lower entrance, we have a little sediment accumulation, while in upper entrance there is degradation behind skimming wall. In lower entrance, the flow is divided into two parts after hitting the channel corner (in coordinates of $10.7 \mathrm{~m}$ for length and 0 for width). One part moves to intake channel, and the other continues to downstream of main channel. In this point that is called rest point, flow depth increases. When the flow hits the corner and section of channel, sediments descend and accumulate in this section. In the second, third and fourth sections, distance between structure and width of 90 , no sediment accumulation exists because of vertical component of velocity and scouring starts in longitudinal distance downstream of this section. In transverse area of 90 to $140 \mathrm{~cm}$, there is settlement in lower entrance.

\section{Effect of skimming wall and spur dike on sedimentation at the intake port}

As can be seen in Fig. 11, with increase in the discharge, the erosion rate of the bed is increased. In the experiments without skimming wall, because of the generation of the secondary currents near the intake port, about 80 to $90 \%$ of the sediment enters the intake, while in experiments with a

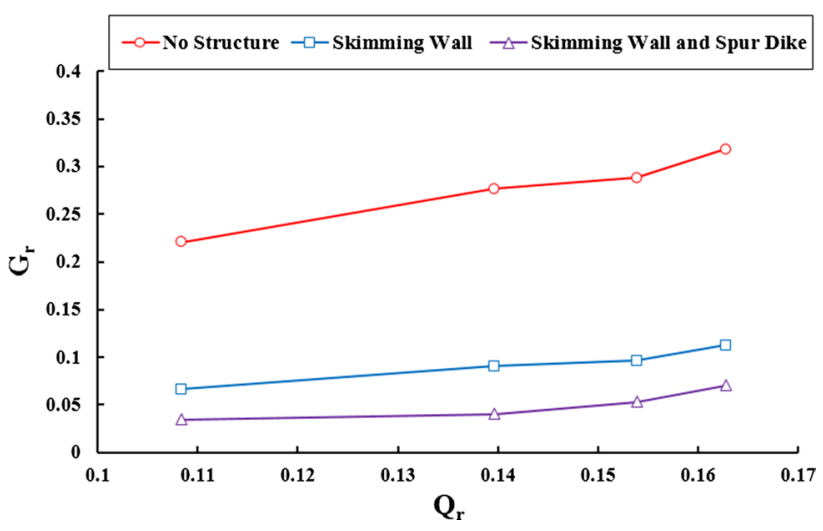

Fig. 11 The ratio of diverted sediment into the intake in terms of intake discharge ratio 
skimming wall, the sedimentation rate is decreased at the intake port. The main reason for these changes may be due to the interference of the secondary current generated by the skimming wall. In the conditions with skimming wall combined with spur dike, the amount of sediment entering the intake has decreased up to $81 \%$. Combining the skimming wall and spur dike has a higher effect on reducing sediments entering the intake (about 15\%) as compared to the condition with using skimming wall alone.

\section{Effects of skimming wall on changes in the velocity distribution near the intake port}

As can be seen in Fig. 12, the skimming wall and spur dike led to some changes in the velocity distribution near the intake port and the removal of the centrifugal force due to a reduction in some part of the flow from the rivers and the reduction in the discharge of the intake.

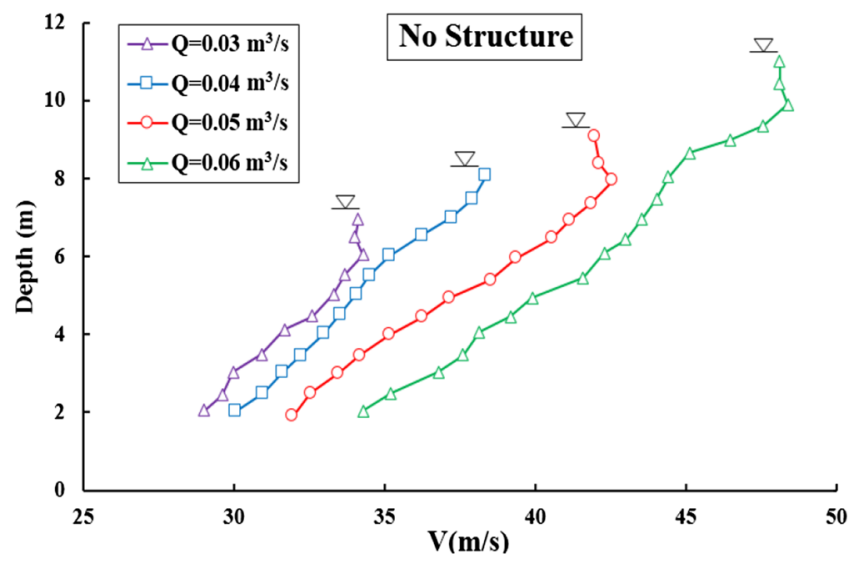

\section{Effects of skimming wall and spur dike on change in position of maximum velocity in the main channel}

Around the spur dike, sediments are removed by increasing the intensity of secondary currents and they are transferred to downstream of the spur dike. Near the spur dike, the vertical component of average velocity is strengthened and washes the sediments and transfers them to downstream of the spur dike. By reducing the sediment depth and increasing the flow depth around the spur dike, its effectiveness on flow diversion is slightly reduced. The flow that extends from the stagnation point downstream of the main channel has a significant vertical velocity component. This flow after collision with the wall of the main channel, a rill is created at downstream with a length of about $70 \mathrm{~cm}$ and a width of $6 \mathrm{~cm}$. Vortices created from this flow move as counter clockwise. Considering the movement of the vortices, the scour depth tents to be larger around the wall of the channel. By moving the flow downstream of the main channel, the intensity of the vortices is reduced and they are gradually disappeared. By installing spur dike on the opposite

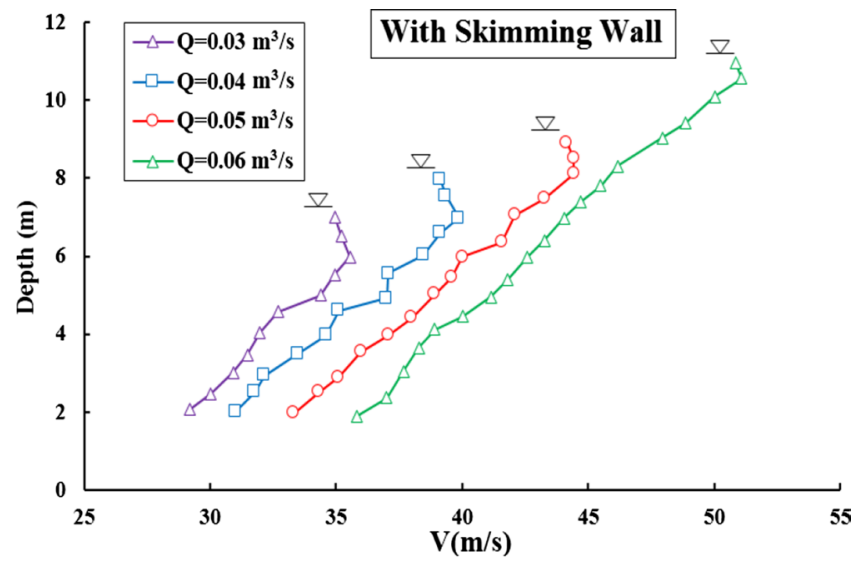

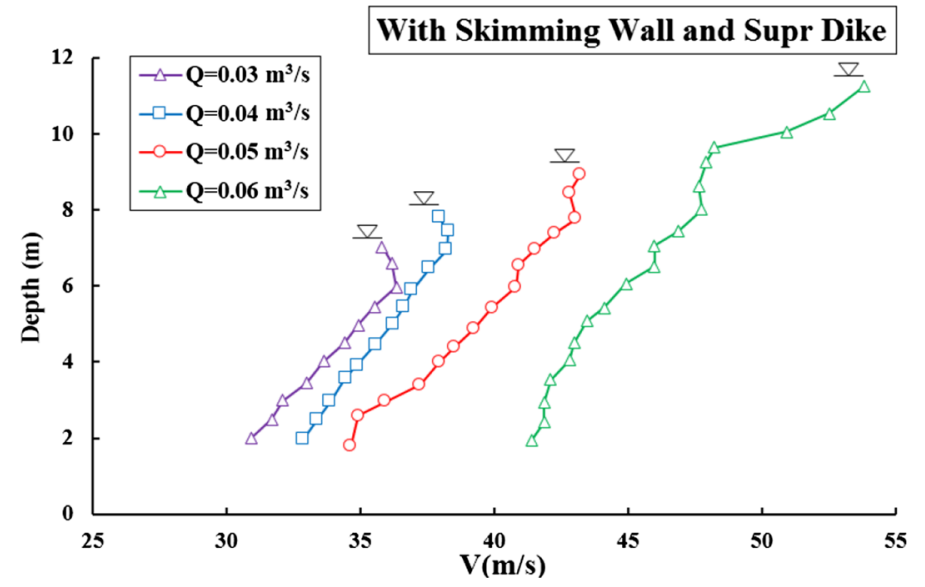

Fig. 12 Velocity distribution near the intake 
bank and upstream of the intake, the longitudinal velocity is increased. As a result, it is prevented from entering sediments into the intake by strengthening the performance of skimming wall vanes and creating strong secondary currents. The secondary currents move on the opposite direction of intake channel and flow along with the intake flow at the surface. Existence of intake and spur dike on the opposite bank causes lateral displacement of maximum velocity and as a result displacement of thalweg. Lateral displacement of maximum velocity begins from upstream of spur dike and in the intake, and reached the maximum amount, due to flow acceleration in the intake area (Fig. 13). The highest value of lateral displacement of maximum velocity is occurred in a rigid bed, slightly lower than spur dike, while such a process cannot be observed in moving bed.

\section{Effects of skimming wall and spur dike on streamlines and isovels $(\mathrm{m} / \mathrm{s})$ in the main channel}

Figure 14 shows streamlines on the plane $(x-y)$, and Fig. 15 shows isovels in the main channel $(\mathrm{m} / \mathrm{s})$ for three conditions of without structures (a), with skimming wall (b), and with skimming wall and spur dike (c). Streamlines are parallel at the beginning of the span, and they are affected after reaching the spur dike and intake. By increasing diversion flow to the intake, the length of the separation zone within the intake port will be decreased. By increasing diversion intake ratios, the created eddy in the plane within the intake moves toward its beginning. Due to the existence of eddies, sediments in the intake are pushed toward its first side. Sedimentation in the intake is reduced by installing the spur dike in the mean channel. The reason for this phenomenon can be attributed to a reduction in the width of the separation line. In the intake channel, the width of the separation line is high at the bottom. Due to high concentration of sediments at the bottom, large amounts of sediments are entered into the intake

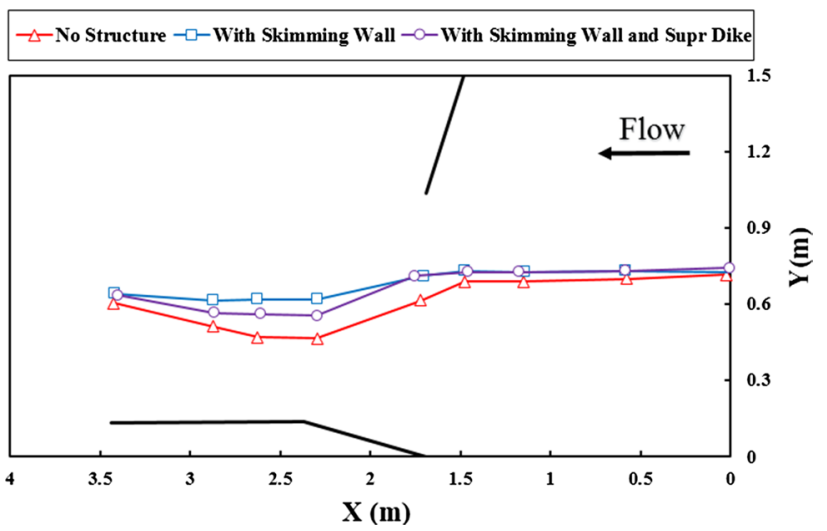

Fig. 13 Change in the location of maximum velocity in the main channel
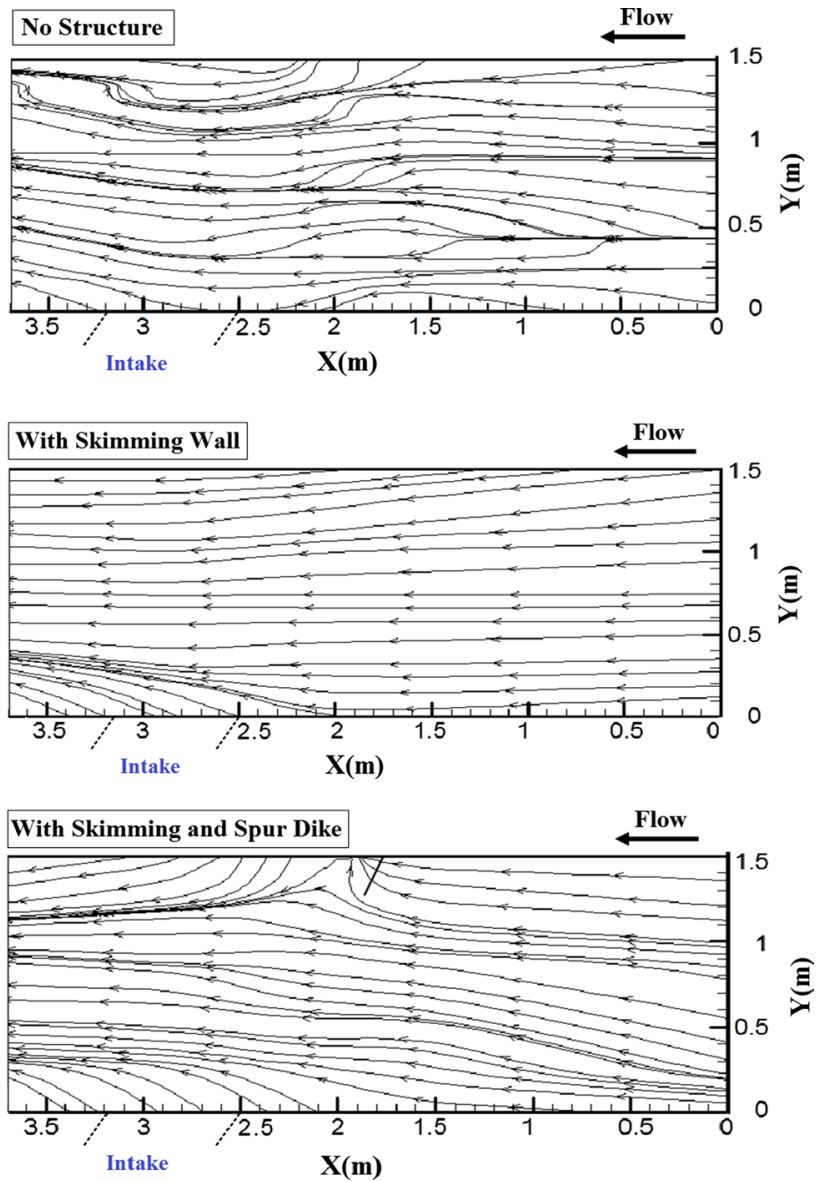

Fig. 14 Streamlines on the plan $(x-y)$

by suction. By installing the skimming wall and spur dike on the opposite side of the intake, width of separation line will be reduced and increased on the channel bottom and water surface, respectively. As a result, the area affected by intake on the channel bottom will be decreased, while the amount of entering sediments to the intake will be reduced. On the other hand, the amount of entering flow to the intake is increased by developing the separation line on the surface. As can be seen in Fig. 15, with the installation of skimming wall vanes at the intake entrance and spur dike on the opposite side of the intake, velocity contour lines (isovels) with high values are drawn into the intake port. The reason for these changes is the creation of tangential velocity. In addition, the velocity concentration has occurred in the upper one-third of the width of intake entrance (from upstream).

\section{Conclusions}

In this paper, the flow pattern and sediment behavior near the intake structures using the spur dike and skimming wall were investigated experimentally in open-channel flow. In order 
Fig. 15 Isovels in the main channel $(\mathrm{m} / \mathrm{s})$
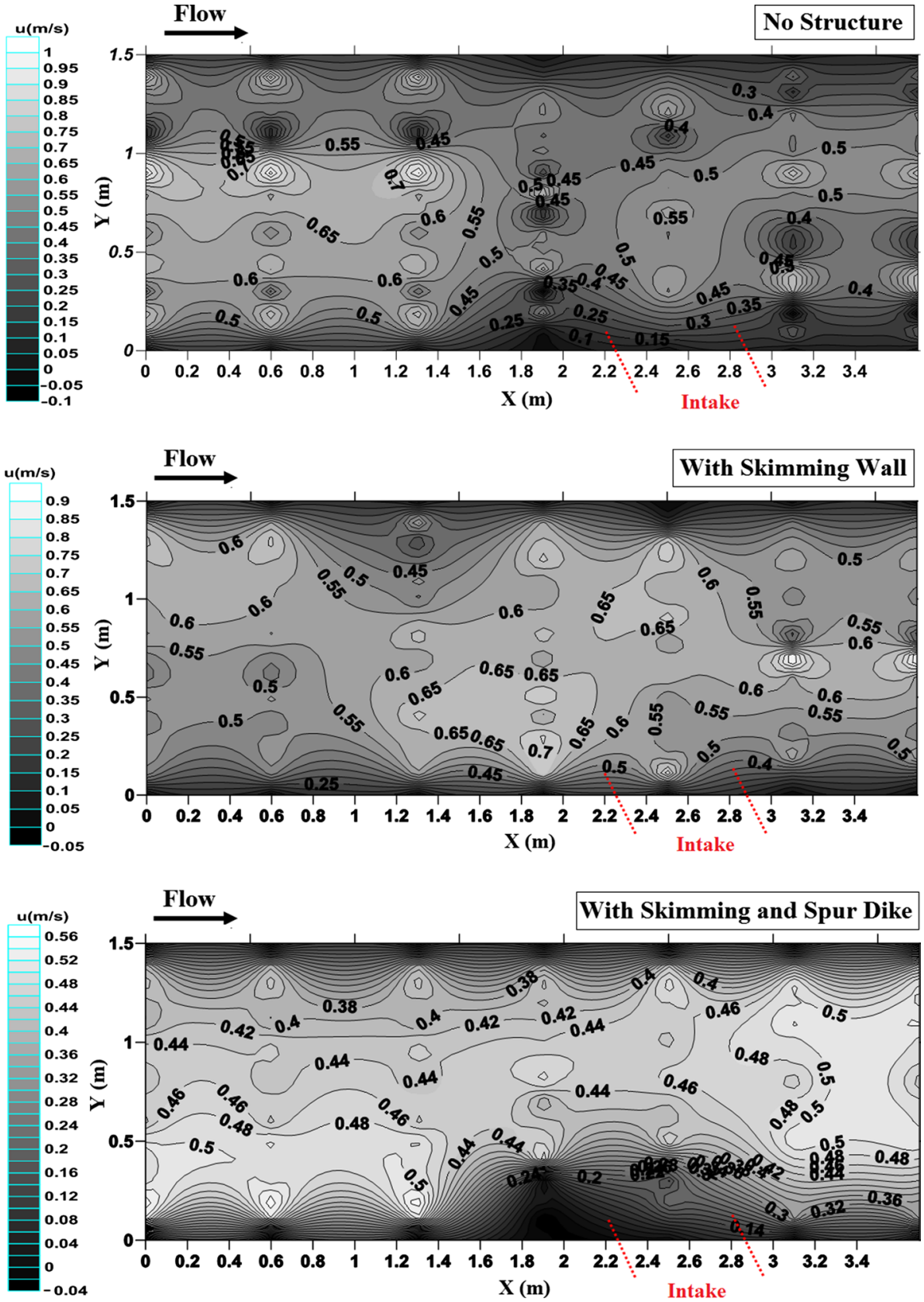

to study the flow patterns in alluvial bed, the bed considered modular, which provides the possibility of better understanding the phenomena governing the process without changing the bed. Width of narrowing area of the flow in intake is reduced from the floor to the water surface. In the narrowing area of the intake, flow depth is minimized and is closed to the critical depth. Despite the secondary currents within the intake, after entering sediment into the intake, they move to the separation zone and then to downstream. By installing the spur dike on the intake, the width of the separation zone will be reduced and increased on the channel bottom and water surface, respectively. As a result, the area affected by the intake on the channel bottom will be decreased, while the amount of entering sediments to the intake will be reduced. In addition, the results showed that by using a skimming wall and spur dike, the thalweg directs toward the intake port. By using the skimming wall and spur dike, a trench is formed toward the intake port. Results showed that in the condition with skimming wall combined with spur dike, the amount of sediment entering the intake decreased up to $81 \%$. Combined skimming wall and spur dike has a higher effect on reducing sediments entering intake (15\%) compared to the conditions with skimming wall alone. 


\section{Compliance with ethical standards}

Conflict of interest The authors declare that they have no conflict of interest.

Ethical approval I certify that this manuscript is original and has not been published and will not be submitted elsewhere for publication while being considered by Applied Water Science. And the study is not split up into several parts to increase the quantity of submissions and submitted to various journals or to one journal over time.

Open Access This article is distributed under the terms of the Creative Commons Attribution 4.0 International License (http://creativeco mmons.org/licenses/by/4.0/), which permits unrestricted use, distribution, and reproduction in any medium, provided you give appropriate credit to the original author(s) and the source, provide a link to the Creative Commons license, and indicate if changes were made.

\section{References}

Barkdoll BD, Ettema R, Odgaard AJ (1999) Sediment control at lateral diversions: limits and enhancements to vane use. J Hydraul Eng 125(8):862-870. https://doi.org/10.1061/ (ASCE)0733-9429(1999)125:8(862)

Choufu L, Abbasi S, Pourshahbaz H, Taghvaei P, Tfwala S (2019) Investigation of flow, erosion, and sedimentation pattern around varied groynes under different hydraulic and geometric conditions: a numerical study. Water 11(2):235

Daneshfaraz R, Ghaderi A, Ghahremanzadeh A (2015) An analysis of flowing pattern around T-shaped spur dike at $90^{\circ}$ arc, based on fluent and flow-3D models. Int Bull Water Resour Dev 3(3):1-9

Daneshfaraz R, Sadeghfam S, Tahni A (2019) Experimental Investigation of Screen as Energy Dissipators in the Movable-Bed Channel. Iran J Sci Technol Trans Civ Eng. https://doi.org/10.1007/s4099 6-019-00306-7

Ghaderi A, Abbasi S (2019) CFD simulation of local scouring around airfoil-shaped bridge piers with and without collar. Sādhanā 44(10): 216

Hosseini D, Torabi M, Moghadam MA (2019) Preference assessment of energy and momentum equations over 2D-SKM method in compound channels. J Water Resour Eng Manag 6(1):24-34
Kuhnle RA, Alonso CV, Shields FD (1999) Geometry of scour holes associated with $90^{\circ}$ spur dikes. J Hydraul Eng 125(9):972-978

Marelius F, Sinha SK (1998) Experimental investigation of flow past submerged vanes. J Hydraul Eng ASCE 124(5):542-545

Moradinejad A, Haghiabi AH, Saneie M, Yonesi H (2017) Investigating the effect of a skimming wall on controlling the sediment entrance at lateral intakes. Water Sci Technol Water Supply 17(4):1121-1132

Nakato T, Kennedy J, Baurely A (1990) Pump-station intake shoaling control with submerged vanes. J Hydraul Eng ASCE 116(1):110-128

Neary V, Sotiropoulos F, Odgaard A (1999) Three-dimensional numerical model of lateral-intake inflows. J Hydraul Eng 125(2):126-140

Odgaard AJ, Kennedy JF (2009) Bed-river bank protection by submerged vanes. J Hydraul Eng ASCE 109(8):1161-1173

Ramamurthy AS, Qu J, Vo D (2007) Numerical and experimental study of dividing open-channel flows. J Hydraul Eng 133(10):1135-1144

Sinha SK, Marelius F (2000) Analysis of flow past submerged vanes. J Hydraul Res 38(1):65-71. https://doi.org/10.1080/0022168000 9498360

Torabi MA, Shafieefar M (2015) An experimental investigation on the stability of foundation of composite vertical breakwaters. J Mar Sci Appl 14(2):175-182

Torabi M, Hamedi A, Alamatian E, Zahabi H (2019) The effect of geometry parameters and flow characteristics on erosion and sedimentation in channel's junction using finite volume method. Int $\mathbf{J}$ Eng Manag Res 9(2):115-123

Wang Y, Odgaard AJ, Melville W, Jain S (1996) Sediment control at water intakes. J Hydraul Eng ASCE 122(6):355-356

Yonesi H, Omid MH, Haghiabi AH (2008) A study of the effects of the longitudinal arrangement sediment behavior near intake structures. J Hydraul Res 46(6):814-819

Zahabi H, Torabi M, Alamatian E, Bahiraei M, Goodarzi M (2018) Effects of geometry and hydraulic characteristics of shallow reservoirs on sediment entrapment. Water 10(12):1725

Publisher's Note Springer Nature remains neutral with regard to jurisdictional claims in published maps and institutional affiliations. 